\title{
Relying on injection drug users to prevent HIV in Ukraine - follow-up results of peer-driven interventions
}

\author{
Oleksandra Datsenko*, Pavlo Smyrnov, Robert Broadhead \\ From 17th International Symposium on HIV and Emerging Infectious Diseases (ISHEID) \\ Marseille, France. 23-25 May 2012
}

\section{Introduction}

Conventional harm reduction (HR) projects overlook IDUs' capabilities in offering them services but no active roles to play in preventing HIV. In contrast, "peer-driven interventions" (PDIs) offer IDUs rewards to educate and recruit peers for services. All IDU-recruits receive the opportunity to play both roles.

\section{Methods}

In 2010, the International HIV/AIDS Alliance-Ukraine implemented PDIs in 12 Ukrainian cities that relied entirely on IDUs to access and teach IDUs who either had: (a.) never received HR services, or (b.) former PDI/HRrespondents eligible for a one-year follow-up (FU) intervention. IDU-recruiters were trained to administer two completely different bodies of prevention information: one to new recruits, the other to FU-recruits. Recruits from both groups were administered an 8-point knowledge test $(\mathrm{KT})$ at their appointment that measured how well their recruiters educated them.

\section{Results}

In 6 months of operation, the 12 PDIs recruited 8,115 IDUs:

2,782 (34\%) new recruits

5,333 (66\%) PDI-FU-recruits

- New recruits: $87 \%$ scored 7 or higher on the first KT

- FU-recruits were administered both KTs at the follow-up appointment.

$86.4 \%$ scored 7 or higher on the 1 st KT

$89.6 \%$ scored 7 or higher on the 2nd KT
(One year earlier, only $81.5 \%$ of the FU-group scored 7 or higher, which underscores how the PDI's repetitive features improved respondents' retention rate.)

\section{Conclusion}

The PDIs documented that IDUs can play active roles in preventing HIV by recruiting IDU-peers who have never received HR services, or IDUs eligible for FU intervention. They are also able to deliver two entirely different bodies of prevention information. Compared to HR projects that relied on traditional staffs of salaried outreach workers, the PDI proved to be far more powerful and cost-effective model. Alliance-Ukraine now plans to broaden its investment in PDIs even more heavily by further expanding projects targeting IDUs, but also female sex workers and homeless/runaway street children.

Published: 25 May 2012

doi:10.1186/1742-4690-9-S1-P104

Cite this article as: Datsenko et al:: Relying on injection drug users to prevent HIV in Ukraine - follow-up results of peer-driven interventions. Retrovirology 2012 9(Suppl 1):P104.

\footnotetext{
* Correspondence: Datsenko@aidsalliance.org.ua

International Hiv-Aids Alliance-Ukraine, Kyiv, Ukraine
}

(c) 2012 Datsenko et al; licensee BioMed Central Ltd. This is an Open Access article distributed under the terms of the Creative 